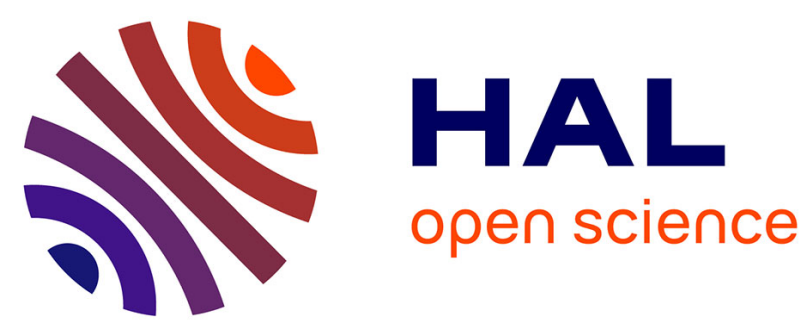

\title{
Investigating a New Operating Point For PV Panels Seeking Maximum Life Span
}

\author{
Bechara Nehme, Nacer K M'Sirdi, Tilda Akiki
}

\section{To cite this version:}

Bechara Nehme, Nacer K M'Sirdi, Tilda Akiki. Investigating a New Operating Point For PV Panels Seeking Maximum Life Span. 2017 IEEE 44th Photovoltaic Specialist Conference (PVSC), Jun 2017, Washington, DC, 2017, pp. 1968-1972., United States. hal-02493608

\section{HAL Id: hal-02493608 https://hal.science/hal-02493608}

Submitted on 28 Feb 2020

HAL is a multi-disciplinary open access archive for the deposit and dissemination of scientific research documents, whether they are published or not. The documents may come from teaching and research institutions in France or abroad, or from public or private research centers.
L'archive ouverte pluridisciplinaire HAL, est destinée au dépôt et à la diffusion de documents scientifiques de niveau recherche, publiés ou non, émanant des établissements d'enseignement et de recherche français ou étrangers, des laboratoires publics ou privés. 


\title{
Investigating a New Operating Point For PV Panels Seeking Maximum Life Span
}

\author{
Bechara Nehme ${ }^{1,2}$, Nacer K. M'Sirdi², Tilda Akiki ${ }^{1}$ \\ ${ }^{1}$ Department of Electrical and Electronics Engineering, Faculty of Engineering, Holy Spirit University of \\ Kaslik (USEK), B.P. 446 Jounieh, Lebanon \\ ${ }^{2}$ Aix Marseille Université, CNRS, ENSAM, Université de Toulon, LSIS UMR 7296, 13397, Marseille \\ France.
}

\begin{abstract}
In this paper we try to control the operation mode of PV panels to achieve a higher lifespan. In fact, PV panels are subject to several degradation modes: Potential Induced Degradation, Light Induced Degradation, UltraViolet Degradation, Moisture Induced Degradation, and cell cracks. The common factor that affects all the above degradation modes is temperature. In fact high temperatures lead to higher degradation process. In this paper we present an enhanced thermal model of PV panels. We simulate its behavior as a function of its operation. We define a new operating point to achieve a higher lifespan.
\end{abstract}

Index Terms - degradation modes, temperature effect, thermal model, joule effect.

\section{INTRODUCTION}

PV (Photovoltaic) panels share in energy production has increased. Their reliability and efficiency consist of two important issues among investors and photovoltaic specialists.

Our previous works focused on reviewing and modeling degradation modes of PV panels [1, 2]. PV panels are subject to PID (Potential Induced Degradation), LID (Light Induced Degradation), UVD (UltraViolet Degradation), MID (Moisture Induced Degradation), and cell cracks. The above mentioned degradation modes are affected by external environmental conditions like: irradiance, relative humidity, and temperature. The common factor is temperature. Besides, these degradations follow Arrhenius equations; they depend exponentially on temperature.

In literature researchers had developed thermal models of PV panels. A. D. JONES and al. developed a thermal model of PV panels based on energy balance [3]. G.M. Tina and al. added the effect of the operating voltage or the extracted power on the thermal energy balance of a PV panel [4]. Ruhi Bharti and al. conducted experiences that showed the effect of the electrical load on the NOCT (Nominal Operating Cell Temperature) [5]. M. Rosa-Clot and al. studied a hybrid thermal-PV panel; the TEPSI (Thermal Electric Solar Panel Integration) [6].
In this paper, we build a more precise thermal model of PV panels in which we take into consideration the effect of electric power generated by the system and the joule effect of the series and shunt resistors of the equivalent circuit. The joule effect is directly linked to the operation point of PV panels. Precisely it depends on the square of the current output and the square of the operational voltage. In the present work we suggest an operating point that leads to decreasing the temperature of PV panels thus mitigating their degradation.

In the following section we will recall the equivalent circuit of PV cell. Then we will develop a thermal model of a PV module. At the end simulation and experimental results will be shown.

\section{EQUIVALENT CIRCUIT OF A PV PANEL}

A PV cell is modeled as a current source $\left(\mathrm{I}_{\mathrm{SC}}\right)$ representing the photo-generated current and depending on the irradiance intensity. Two diodes D1 and D2 are mounted in inverse parallel with the current source and represent the recombination current happening in the neutral region and in the depletion region. A parallel shunt resistor $\left(R_{\text {sh }}\right)$ models the leakage current. All the above are connected in series with a resistor $\left(\mathrm{R}_{\mathrm{s}}\right)$ that represents the resistance of the front grid and of the interconnects. Having a panel constituted of $n$ series cells, their series resistances will be added to have an equivalent series resistance of $n \times R_{s}$.

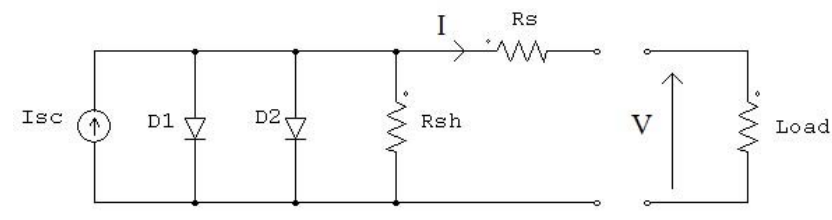

Fig. 1. Electric equivalent circuit of a PV cell.

The output current of the PV cell is given by the following formula: 


$$
\begin{gathered}
I=I_{S C}-I_{01} \times\left(\exp \left(\frac{q \times\left(V_{c}+R_{s} \times I\right)}{K_{B} \times T_{p v}}\right)-1\right) \\
-I_{02} \times\left(\exp \left(\frac{q \times\left(V_{c}+R_{s} \times I\right)}{2 \times K_{B} \times T_{p v}}\right)-1\right)-\frac{V_{c}+R_{s} \times I}{R_{s h}}
\end{gathered}
$$

Where:

$I_{S C}:$ is the photo-generated current in A.

$I_{01}$ : the dark saturation current (in neutral region) in A.

$I_{02}$ : the dark saturation current (in depletion region) in A.

$R_{s} \quad$ : series resistance in $\Omega$.

$R_{\text {sh }}$ : shunt resistance in $\Omega$.

$V_{c} \quad$ : the output voltage of the cell in $\mathrm{V}$.

$q$ : electron charge $1.602 \times 10^{-19} \mathrm{C}$.

$K_{B}$ : Boltzmann constant $1.3806488 \times 10^{-23} \mathrm{~m}^{2} \cdot \mathrm{kg} \cdot \mathrm{s}^{-2} \cdot \mathrm{K}^{-1}$.

\section{THERMAL MODEL OF A PV PANEL}

A PV panel resembles a flat plate that receives solar irradiation and generates electrical power. The incident irradiation is reduced due to reflection. The electrical output power generated by the PV panel depends on its operating voltage. In fact, the P-V characteristic is non linear and presents a mountain shape. The electric output power represents a sink to the thermal system model. The output electric power of a PV panel is given by the following formula:

$$
P_{\text {ele }}=V \times I \leq 0.18 \times P_{\text {sol }}
$$

Where:

$\mathrm{P} \quad$ : electric output power in $\mathrm{W}$.

$\mathrm{V}$ : operating voltage of the panel in $\mathrm{V}$.

I : current of the panel in A.

$P_{\text {sol }}:$ total solar power in $\mathrm{W}$.

The conversion efficiency of conventional PV panels is limited to $18 \%$. The remaining input power will generate heat to the panel. This heat will be dissipated to the exterior via convection and radiation [7]. The conduction is neglected because the panel nearly presents no contact to solids.

The thermal convection flux to ambient air is expressed by the following formula:

$$
\dot{Q}_{c o n v}=h \times\left(T_{a m b}-T_{p v}\right)
$$

Where:

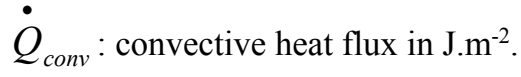

$h:$ heat transfer coefficient in $\mathrm{W} \cdot \mathrm{m}^{-2} \cdot \mathrm{K}^{-1}$.

$T_{a m b}:$ ambient temperature in $\mathrm{K}$.

$T_{p v}: \mathrm{PV}$ panel temperature in $\mathrm{K}$.

The heat transfer coefficient depends on many parameters: The wind velocity, the air density, the tilt angle and the dimensions of the panel. The latter parameters are hard or costly to control; this defends our strategy in controlling the electrical operating point of the panel.

The thermal radiation flux is expressed by the following formula:

$$
\dot{Q}_{r a d}=\varepsilon \times \sigma \times\left(\mathrm{T}_{a m b}^{4}-\mathrm{T}_{p v s}^{4}\right)
$$

Where:

$$
\begin{aligned}
& \dot{Q}_{r a d}: \text { radiative heat flux in } \mathrm{J} \cdot \mathrm{m}^{-2} . \\
& \mathcal{E} \quad: \text { emissivity. } \\
& \sigma \quad: \text { Stephan-Boltzmann constant } 5.67 \times 10^{-8} \mathrm{~W} \cdot \mathrm{m}^{-2} \cdot \mathrm{K}^{-4} . \\
& T_{p v s}: \text { PV panel surface temperature in } \mathrm{K} .
\end{aligned}
$$

The front surface emissivity is taken as 0.9 , the back surface emissivity is taken as 0.84 [3].

In our model we add the effect of the series resistance and the shunt resistance that heat the PV panel by the Joule effect. The internal heat sources of the panel are due to the Joule effect of the series and shunt resistors. In fact, current passing through the printed $\mathrm{Ag}$ fingers and through the $\mathrm{Cu}$ bus-bars will lead to a localized heat generation modeled by the series resistor $\mathrm{R}_{\mathrm{s}}$. Besides, current passing through a path around the cell will lead to a localized heat generation modeled by the series resistor $R_{\text {sh. }}$. The joule effect is given by the following formula:

$$
P_{j}=n \times R_{s} \times I^{2}+n \times \frac{\left(V / n+R_{s} \times I\right)^{2}}{R_{s h}}
$$

Where:

$P_{j}:$ Joule's power in $\mathrm{W}$.

$n:$ number of cells.

The PV panel receives two heat sources: The incident irradiance and the internal joule generated heat. The panel generates electrical power to the load and dissipates power by 
convection and radiation. The thermal energy balance of a PV panel can be illustrated in figure 2 .

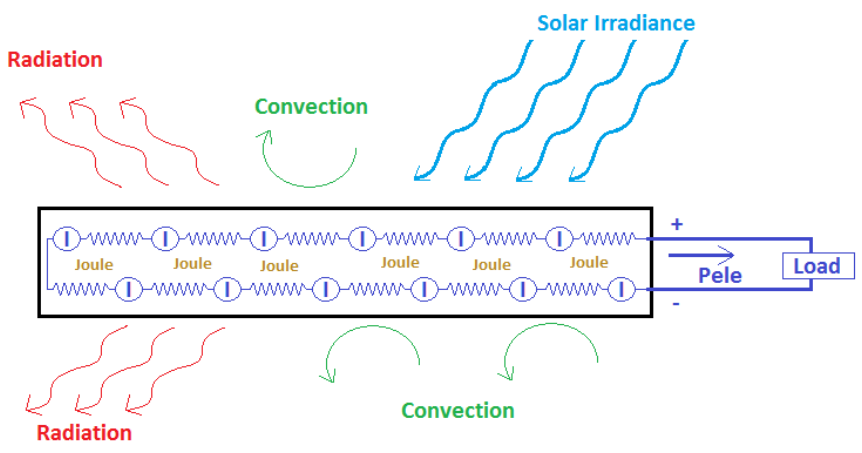

Fig. 2. Thermal energy balance of a PV panel.

\section{SIMULATION RESULTS}

We built a thermal model of a PV panel using Comsol software. The wind velocity is set to $1 \mathrm{~m} . \mathrm{s}^{-1}$. The panel is horizontal. The panel dimensions are $1.2 \mathrm{~m} \times 0.54 \mathrm{~m} \times 0.01 \mathrm{~m}$. It is constituted of 36 cells in parallel. Under STC, it can deliver $5.5 \mathrm{~A}$ and $100 \mathrm{~W}$. The radiation heat dissipation happens from the front and back surfaces. The emissivity of the front surface is taken as 0.9 and that of the back surface is taken as 0.84 . The operating voltage of the panel was swept from $2 \mathrm{~V}$ to $21 \mathrm{~V}$ with a step of $0.1 \mathrm{~V}$. The input power irradiance is swept from $100 \mathrm{~W} . \mathrm{m}^{-2}$ to $1100 \mathrm{~W} . \mathrm{m}^{-2}$ with a step of $100 \mathrm{~W} . \mathrm{m}^{-2}$. For each operating point, the temperature is calculated. Results are shown in Fig. 4.

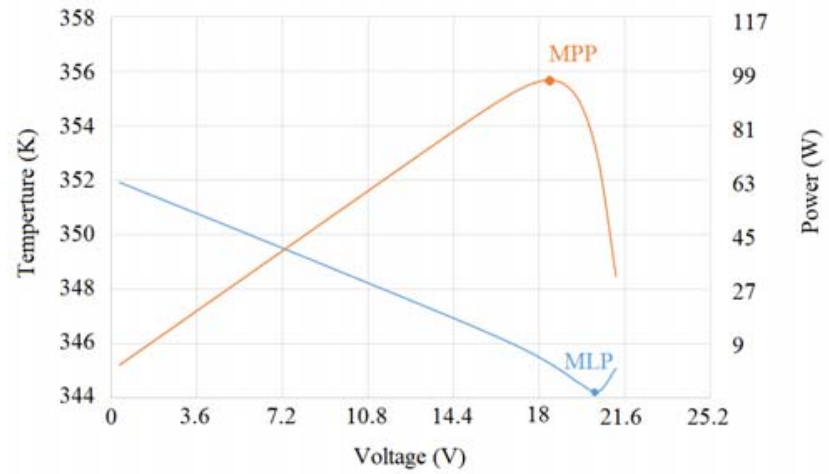

Fig. 3. Output power in orange and panel's temperature in blue.

We can see that the minimum temperature is reached for a voltage of $20.52 \mathrm{~V}$ even though the MPP (Maximum power point) is located at $18.36 \mathrm{~V}$.

We locate a point of operation that will operate the panel at a lower temperature; thus giving longer life span. We call this point the MLP (Maximum Life Point). This point is always at a higher voltage than the MPP. Comparing the MLP with the MPP we can see a reduction of around 19\% in power production and a decrease of around 1.5 degrees in temperature.

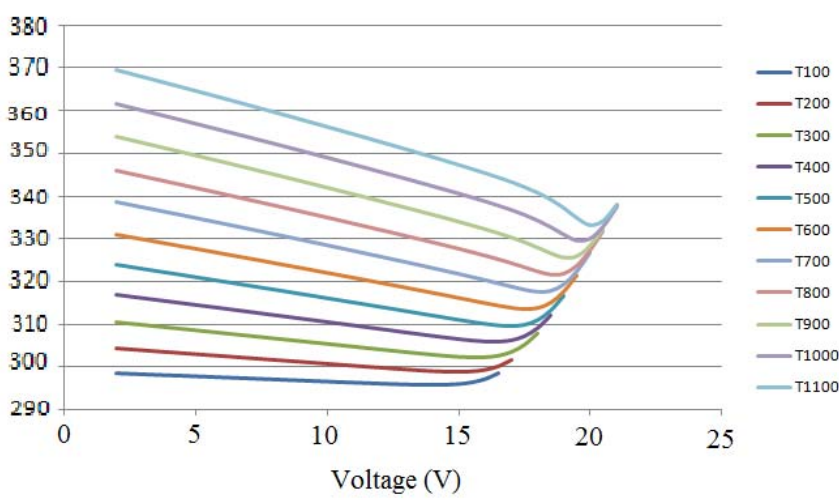

Fig. 4. Panel temperature for different irradiations and operating points.

We can see from figure 4 that our approach works fine for different illumination levels. From here future perspectives derive to choose when to operate at MPP or at reduced temperature.

Additional information is gathered from the developed model. In fact, a small difference in temperature is noted between the center of the panel and the edge of the panel. Temperature is higher at the center of the panel. The latter is highlighted in figure 5 where we show the temperature repartition at the front surface of the panel.

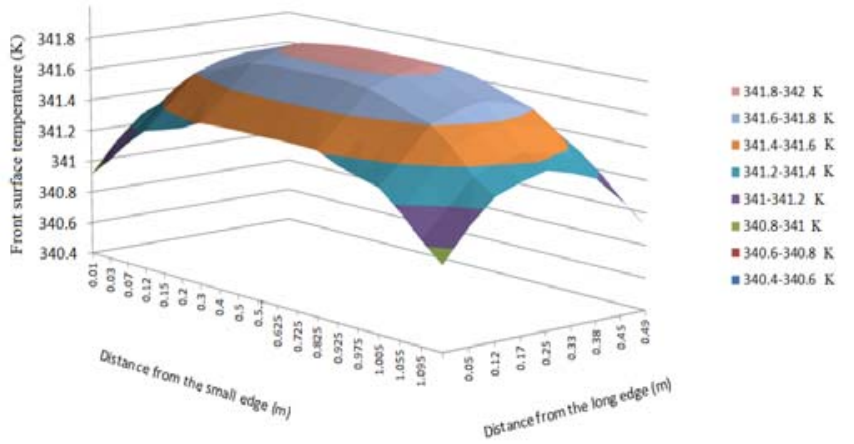

Fig. 5. Front surface temperature of the Panel.

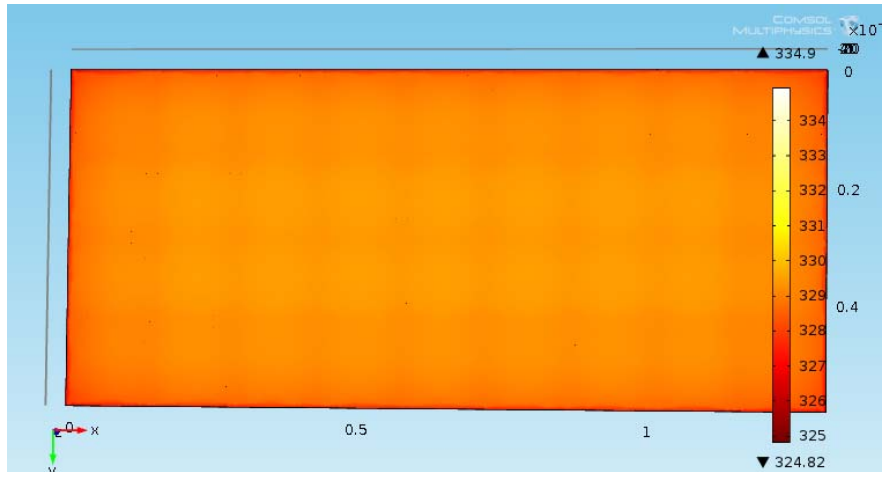

Fig. 6. Intercell and cell temperature at the front surface. 
In addition, cells regions presented higher temperature than intercell regions. This is explained by the fact that in cell regions, a localized heat source is present $\left(R_{s}\right.$ and $\left.R_{s h}\right)$. The results are shown in figure 6.

\section{EXPERIMENTAL RESULTS}

In order to validate the simulation results we built an experimental apparatus. The indoor apparatus can emulate the external conditions and record the temperature of the panel. We built a PV system composed of a $100 \mathrm{~W}$ PV panel (Monochrystalline, Solar Innova SI-ESF-M-M90-100W), halogen projectors, resistive load, DC/DC converter, and back surface mounted thermocouples. Two thermocouples are used to measure the temperature of the panel. Their average temperature is noted. The $\mathrm{DC} / \mathrm{DC}$ converter is used to vary the operating voltage of the panel. A variation in the operating voltage gave the following results (figure 7) that matched our previous simulation results:

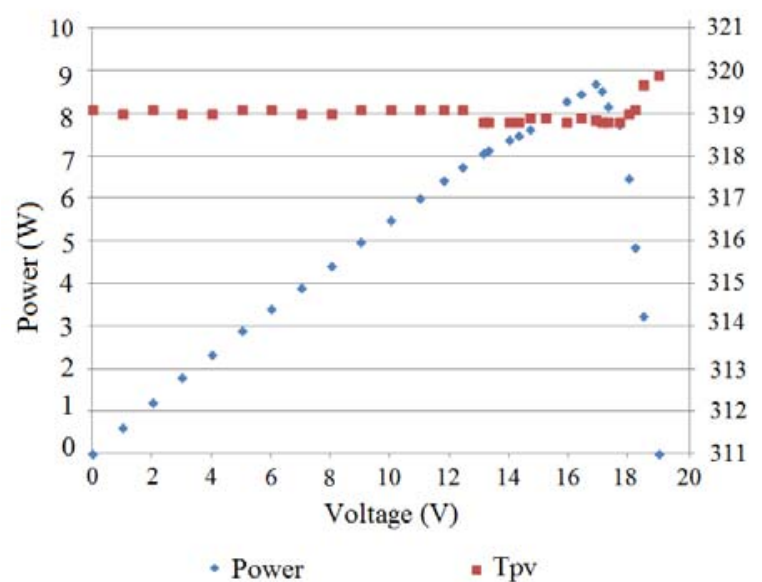

Fig. 7. Experimental output power in green and panel's temperature in red.

A second experimentation was performed with variable wind speed. Two fans were implemented. The ambient temperature is $27^{\circ} \mathrm{C}$, and the relative humidity is $92 \%$. The results show the same thermal behavior. Figures 8, 9, and 10 present the experimentation results with low, medium, and high wind speeds respectively. We can see that the temperature of the back of the cell (points in red) is higher than the temperature of the back of the spaces between the cells (points in green). The latter aligns with the simulation results shown in figure 6 .

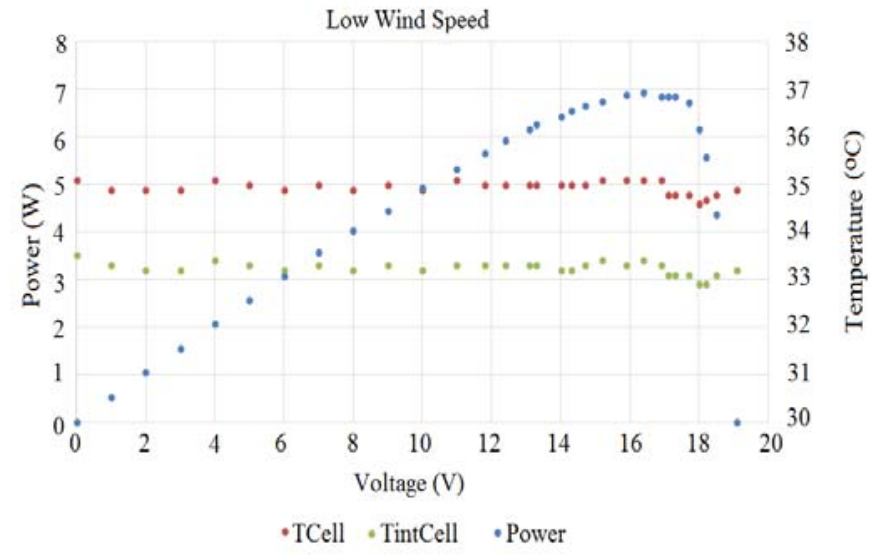

Fig. 8. Thermal behavior of the PV panel as a function of the operating voltage with low wind speed.

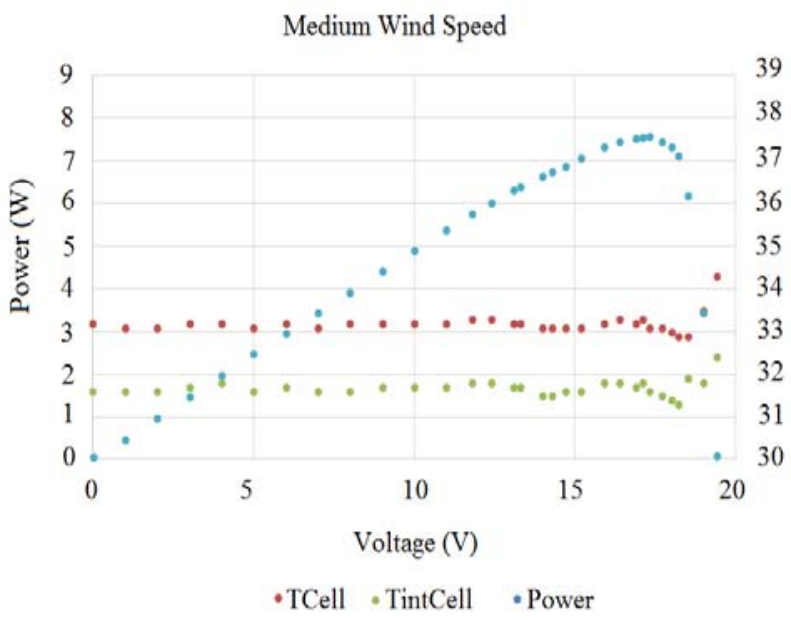

Fig. 9. Thermal behavior of the PV panel as a function of the operating voltage with medium wind speed.

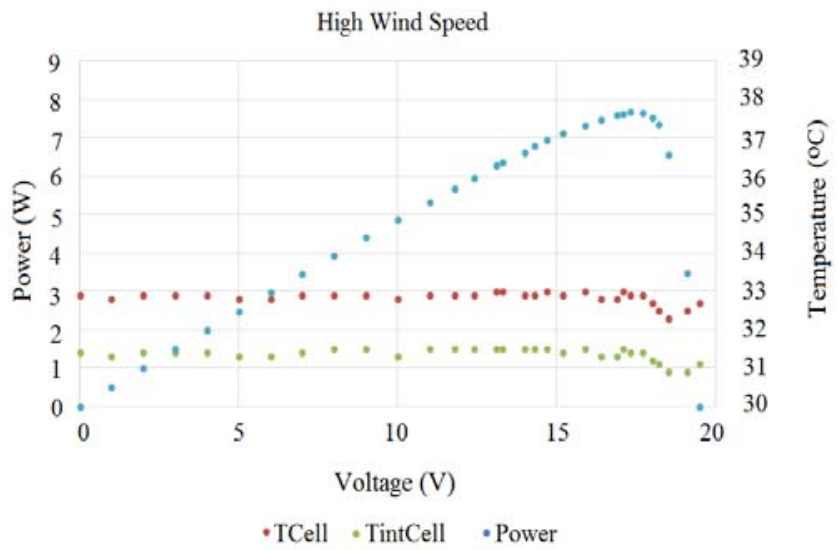

Fig. 10. Thermal behavior of the PV panel as a function of the operating voltage with high wind speed. 


\section{DISCUSSION}

In this paper, we presented a new thermal model of PV panels. To the existing models developed in literature we added the effect of internal heat sources emerging from the series and shunt resistors. The model has been validated using an experimental apparatus. The apparatus needs to be enhanced to get higher irradiance, and the equivalent temperature of the lights must meet solar spectrum.

A new point (MLP) of operation of PV panels has been identified where the panel will operate at lower temperature which yields lower degradation rates and thus higher lifespan of PV panels.

\section{CONCLUSION}

Degradation of PV panel has become a major concern for investors. In this paper we reached to find an operating point that will lead to increasing the life span of PV panels. In reality, degradation is exponentially affected by temperature. In our study we developed a thermal model for PV panels taking into consideration the joule effect of the series resistor. A point located at the right of the MPP corresponds to our investigation. In future works we will develop an algorithm which objective is to alleviate the degradation process of PV panels without losing high power generation.

\section{ACKNOWLEDGMENT}

The authors would like to thank the AUF (Agence Universitaire de la Francophonie) and the HCR (Higher Center of Research) of USEK University for their financial support.

\section{REFERENCES}

[1] B. Nehme, N. K. M'Sirdi, T. Akiki, and A. Naamane, "Contribution to the modeling of ageing effects in pv cells and modules," Energy Procedia, vol. 62, pp. 565-575, 2014.

[2] B. Nehme, N. K. M'Sirdi, and T. Akiki, "A geometric approach for pv modules degradation," to be published in REDEC-2014.

[3] Jones A. D., and C. P. Underwood, "A thermal model for photovoltaic systems," Solar Energy EDEC-2014, vol. 70.4, pp. 349-359, 2001.

[4] Tina GM, and Scrofani S, "Electrical and thermal model for PV module temperature evaluation," Electrotechnical Conference, 2008. MELECOM 2008. The $14^{\text {th }}$ IEEE Mediterranean.

[5] R. Bharti, J. Kuitche, and M. G. TamizhMani, "Nominal operating cell temperature (NOCT): effects of module size, loading and solar spectrum," Photovoltaic specialists conference, 2009. $34^{\text {th }}$ IEEE PVSC2009, p. 001657.

[6] M. Rosa-Clot, P. Rosa-Clot, and G. M. Tina, "TEPSI: Thermal Electric Solar Panel Integration," Solar Energy, vol. 85, pp. 2433-2442, 2011.

[7] F. M. White, Heat and Mass Transfer. USA: Addison Wesley, 1991. 